(2) Open Access Full Text Article

REVIEW

\title{
Update on emerging regional techniques and novel local anesthetics in ambulatory anesthesia
}

\section{Martin J Szafran \\ Eldhose Abrahams \\ Tong Joo Gan}

Department of Anesthesiology, Stony Brook University, Stony Brook, NY, USA
Correspondence: Tong Joo Gan Department of Anesthesiology, Stony Brook University, HSC Level 4, Rm 060, Stony Brook, NY I 1794-8480, USA

Tel + I 63I 4442979

Fax + I 63| 4442907

Email tong.gan@stonybrookmedicine.edu
This article was published in the following Dove Press journal:

Ambulatory Anesthesia

18 December 2015

Number of times this article has been viewed
Abstract: New regional anesthetic techniques have been incorporated into the multimodal approach to postoperative analgesia. Blocks such as the transversus abdominis plane block, adductor canal block, and pectoral nerves blocks all show promise as potential tools used in opioid-sparing techniques, but at the same time have significant limitations to their utility. Novel long-acting formulations of local anesthetics further add to the possible benefit of these blocks, but their application to peripheral nerve blocks is currently being investigated and is not well defined. This review focuses on evaluating the relevant anatomy, technique, and indications of several newer peripheral nerve blocks, the emerging evidence supporting the use of liposomal bupivacaine and $\mathrm{SABER}^{\circledR}$-Bupivacaine, and the application of both in ambulatory anesthesia. Keywords: transversus abdominis plane (TAP) block, adductor canal block, pectoral nerves block, regional anesthesia, liposomal bupivacaine, SABER ${ }^{\circledR}$-Bupivacaine

\section{Introduction}

The drastic increase in ambulatory surgery volume is well documented, with the number of cases rising from 20 to 34 million between the years 1996 and 2006. ${ }^{1}$ A larger percentage of cases being performed in the ambulatory setting presents anesthesiologists with the challenge of providing a safe, quick, and reliable anesthetic and recovery plan. Innovations in surgical procedures allow surgeons to operate on a wider variety of outpatients, further raising the expectations placed on anesthesiologists.

The multimodal analgesic plan and opioid-sparing techniques are central themes in administering an anesthetic with minimal side effects that allows safe and quick recovery and discharge. Regional anesthesia is an integral part of this plan, and it has been ubiquitously employed to prevent opioid-induced nausea, ${ }^{2}$ to shorten recovery times relative to general anesthesia and narcotic techniques, ${ }^{3,4}$ and to improve patient satisfaction. Novel regional anesthetic techniques utilized by anesthesia providers can be a valuable tool in providing the optimal anesthetic plan.

Ultrasound-guided (USG) peripheral nerve blocks (PNBs) are continually being refined, with innovative applications found for preexisting blocks. Currently, PNBs come with limitations. Single-injection blocks typically provide from 8 to 24 hours of pain relief, which oftentimes is not adequate and produces challenges in managing postoperative pain. Continuous PNBs (CPNBs) have been utilized in both inpatient and outpatient settings as a potential solution to this problem, but also have drawbacks and potential complications. ${ }^{5}$ Appropriate placement of CPNBs requires additional skill and time, and providers typically feel more comfortable performing a single-injection PNB. The application of CPNBs is limited to a smaller, healthier patient pool, at times 
excluding patients with cognitive dysfunction, severe cardiopulmonary disease, and other comorbidities that may delay identification of catheter placement complications. Other considerations must be evaluated prior to CPNB placement in the ambulatory environment, with many patients potentially requiring additional caretaker help or appropriate family assistance. ${ }^{6,7}$ Finally, removal of catheters at home may be not as benign a process as previously thought. ${ }^{8}$ The additional complexity and limitations of placing CPNBs have led many providers to avoid these techniques altogether in the outpatient setting.

The development of long-acting local anesthetic formulations shows promise, but these have been primarily utilized in local wound infiltration by the surgeon. The application of these formulations to regional anesthesia is in the very early stages of research. In this article, several newer regional anesthetic blocks and their indications in ambulatory surgery will be reviewed, including the transversus abdominis plane (TAP) block, adductor canal (AC) block (ACB), and pectoral nerves blocks. In the Novel local anesthetic formulations section, both liposomal bupivacaine and SABER ${ }^{\circledR}$-Bupivacaine are reviewed, with the focus on their application to regional anesthetic techniques.

\section{TAP block}

Abdominal wall nerve blocks such as the TAP block are not novel blocks, but their popularity and utility have greatly increased over the last several years. Initially it was described by Rafi in 2001 as a "single pop" PNB technique covering the relevant sensory nerves of the abdominal wall. ${ }^{9}$ Subsequently, the landmark approach has been modified and popularized by the addition of USG techniques. The relative ease and safety of the TAP block have made it a more ubiquitous tool in the management of postoperative abdominal pain, especially in situations where narcotic-sparing techniques are desired. Currently, the TAP block is utilized in both major abdominal surgeries and outpatient procedures, and, furthermore, it has been incorporated successfully into enhanced recovery pathways. ${ }^{10,11}$ Despite the vast application of this block, randomized controlled trials show mixed results when applied to outpatient abdominal wall surgery. This review focuses on the anatomy and techniques of the TAP block and its potential indications in ambulatory surgery.

\section{Anatomy and techniques}

The TAP block anatomy is ultimately defined by the neurovascular plane between the internal oblique and transversus abdominis muscles. The method by which local anesthetics are deposited in this plane has evolved over time, but the goal has remained constant. Although the differences in the approaches may be subtle, the spread of local anesthetic and quality of block can vary drastically; thus, understanding the abdominal wall anatomy and nomenclature is crucial to a successful application of this block. ${ }^{12}$

The landmark-guided techniques involve understanding the triangle of Petit anatomy. The triangle of Petit is defined as the anatomical area that is formed by the latissimus dorsi margin posteriorly, external oblique margin anteriorly, and the iliac crest inferiorly, to which the aforementioned muscles attach. The floor of the triangle of Petit is formed by the internal oblique muscle.

The initial description of the block by Rafi relied on the palpation of latissimus dorsi attachment to the iliac crest and having a good feel for needle position. The needle insertion point is within the triangle of Petit just anterior to the latissimus dorsi attachment, with the goal of the needle tip making contact with the iliac crest past the fascial attachment of the external oblique muscle. Ultimately, the needle is walked off the crest and a change of resistance is felt when the needle enters the targeted neurovascular plane between the internal oblique and transversus abdominis muscles. As is common practice today, the use of a blunt needle and a larger volume $(20 \mathrm{~mL})$ of local anesthetic were recommended. ${ }^{9}$

The "double-pop" technique is a variation of the singlepop technique, and was initially described by McDonnell et al. ${ }^{13}$ The needle insertion is still within the triangle of Petit and posterior to the midaxillary line, but superior to the iliac crest attachments. The change in resistance is felt twice - first when passing through the fascial plane of the external oblique, and second when entering the plane past the internal oblique. McDonnell et al not only described this technique, but went on to show its benefits in various surgeries involving the anterior abdominal wall. ${ }^{14,15}$

Although this technique is relatively easy to learn, it is not without technical challenges and possible complications. The variation in triangle of Petit position is well documented and is not always easily palpated, especially in obese patients. ${ }^{16}$ This can lead to depositing the local anesthetic superficial to the targeted plane, as well as the unintentional puncture of peritoneum or visceral organs. ${ }^{17}$ An explanation offered by Rafi is that the change in resistance, or "first pop", expected going through the external oblique fascial plane is subtle and easily missed. ${ }^{18}$

The use of ultrasound guidance has gained widespread acceptance within the regional anesthesia community, allowing for visual confirmation when performing a nerve block. 
The popularity of ultrasound use, in combination with potential operator-driven limitations of landmark techniques, has led to the development of USG TAP blocks. The initial description is attributed to Hebbard et al. ${ }^{19}$ This block is performed with the ultrasound probe perpendicular to the midaxillary line between the iliac crest and subcostal margin, with in-plane needle insertion from anteromedial to posterolateral direction. Most often, this approach is referred to as the USG lateral midaxillary approach, but also has been associated with other confusing nomenclature such as USG triangle of Petit approach, USG classic approach, and even, at times, USG posterior approach.

Anatomical studies have revealed a difference in local anesthetic spread when comparing the landmark techniques to the updated USG lateral technique. Sensory innervation may adequately be blocked for upper abdominal, lower abdominal, and pelvic surgeries when performing the landmark approach. ${ }^{20}$ The inclusion of dermatomes can range from as high as $\mathrm{T} 7$ to as low as L1. Randomized controlled trials evaluating the utility of the lateral USG approach have shown mixed results. ${ }^{20}$ It may be simply that the classic USG lateral midaxillary approach is not posterior enough, potentially sparing some thoracoabdominal cutaneous branches, with the landmark approach having components of a paravertebral block. ${ }^{21}$

For improved coverage of dermatomes cephalad to the umbilicus, a subcostal USG approach was described. ${ }^{22}$ In this approach, the ultrasound probe is oblique, inferior to the anterior costal margin, with in-plane needle placement and the target being the neurovascular plane between the rectus abdominis and the transversus abdominis. Dermatomal coverage as high as T6 has been reported with this variation on the block, showing promise for utility of USG blocks in upper abdominal surgery. ${ }^{23}$ Another variation of the USG TAP block exists that is referred to as the posterior USG TAP block or quadratus lumborum block. Initially described by Blanco in 2007, it was subsequently published in a case report. ${ }^{24,25}$ Although currently not the most popular variation of the TAP block, it may be the ultrasound alternative for the more successful posterior landmark approaches. It involves moving the probe posterior to the lateral USG position and depositing local anesthetic in the plane between the transversus abdominis aponeurosis and the quadratus lumborum. Unfortunately, this block is currently lacking significant published evidence of its benefits.

\section{Indications}

Initial landmark techniques have shown great results in improving visual analog scale (VAS) scores for pain and lowering opioid requirements for major lower abdominal and pelvic surgeries. ${ }^{14,15}$ With the transition to USG TAP block techniques, one has to take into account the anatomical restraints of each type of block. In the ambulatory setting, the TAP block has been utilized for several types of surgery, most commonly laparoscopic procedures such as cholecystectomy and minor gynecological procedures, as well as inguinal hernia repairs. Although the TAP block has mainly been evaluated in the inpatient setting, certain results can be applied to the outpatient population.

\section{Laparoscopic cholecystectomy} Lateral midaxillary USG TAP block

Petersen et al, in one of the larger randomized, placebocontrolled studies, was able to show significant difference in early opioid consumption (0-2 hours, $7.5 \mathrm{mg}$ vs $5 \mathrm{mg}$, $P<0.001)$ in patients receiving USG TAP block vs a placebo block. ${ }^{26}$ The primary outcome was area under the curve (AUC) pain scores with coughing in the first 24 hours, where a difference was noted ( $26 \mathrm{~mm}$ vs $34 \mathrm{~mm}, P<0.04$ ), with the difference being negligible at 24 hours postoperatively. Unfortunately, no difference in opioid consumption in the 24-hour postoperative period was noted, putting in question the prolonged benefits of TAP blocks. When compared to placebo, other studies resulted in more pronounced opioidsparing benefits of TAP blocks. El-Dawlatly et al showed decreased intraoperative sufentanil requirement, as well as decreased morphine patient-controlled analgesic use in the recovery area and in the initial 24 hours postoperatively. ${ }^{27}$ $\mathrm{Ra}$ et al demonstrated decreased postoperative opioid consumption and improved pain scores up to 24 hours after surgery in patients receiving TAP blocks with both $0.25 \%$ and $0.5 \%$ levobupivacaine. ${ }^{28}$ The conflicting results leave the extended benefit of TAP blocks in this setting open to debate.

When TAP block was compared to trocar site infiltration, Ortiz et al failed to show any significant difference between the groups at 4 hours after surgery $(P=0.18)$ or at 24 hours after surgery $(P=0.23) .{ }^{29}$ Also, no difference was noted in 24-hour opioid consumption, adding to the concern that TAP block and the risks associated with it may not be indicated if the surgical wound site is infiltrated with local anesthetics by the surgeon.

\section{Oblique subcostal USG TAP block}

Laparoscopic cholecystectomies typically involve supraumbilical trocar insertion; thus the subcostal approach to TAP block may be more beneficial in covering the cephalad dermatomes spared by the lateral USG approach. 
Unfortunately, only limited, smaller studies exist evaluating this potential benefit. ${ }^{30-32}$ Chen et al compared subcostal TAP to patients receiving a $0.1 \mathrm{mg} / \mathrm{kg}$ dose of morphine post-induction in the control group, showing no significant difference in intraoperative opioid use, with limited data on postoperative opioid use. ${ }^{30}$

Bhatia et al compared patients receiving lateral TAP block to subcostal TAP block, and were able to demonstrate significant improvement in the subcostal approach when evaluating postoperative pain scores (VAS score at 24 hours, $1.7 \pm 1.3 \mathrm{vs}$ $0.5 \pm 0.8$ ), and 24-hour opioid consumption ( $89.0 \pm 80.6 \mathrm{mg}$ vs $27.0 \pm 49.5 \mathrm{mg}) .{ }^{31}$ Interestingly, Tolchard et al demonstrated an immediate opioid-sparing benefit to subcostal TAP block over port site local anesthetic infiltration, with lower recovery room fentanyl use (median $0.9 \mathrm{vs} 1.5 \mu \mathrm{g} / \mathrm{kg}$ ) and morphine consumption in the initial 8 hours after surgery (median $10 \mathrm{mg}$ vs $19 \mathrm{mg}){ }^{32}$ These results support the idea that that the subcostal approach may be the more appropriate variation of the TAP block when managing patients undergoing cholecystectomy.

It is also important to note that pain intensity is considered to be worst in the period 24-48 hours after cholecystectomy. ${ }^{33}$ This consideration makes the use of long-acting local anesthetic formulations especially appealing when planning the regional anesthetic technique for laparoscopic cholecystectomy.

\section{Inguinal hernia repair}

Inguinal hernia repair is an outpatient surgery that may result in significant postoperative pain. The ilioinguinal/ iliohypogastric (II/IH) nerve block is a frequent part of the analgesic plan, and USG techniques have been shown to improve postoperative pain scores compared to placebo. ${ }^{34}$ The role of TAP blocks is not clearly defined, with the results mixed. The classic lateral USG approach is ineffective if L1 dermatome is spared, but in theory the TAP block may offer a prolonged duration compared to II/IH block.

Aveline et al were able to produce results that hinted at the potential advantage of TAP block in open inguinal hernia repair. ${ }^{35}$ Median VAS scores at rest were improved with the USG lateral technique compared to II/IH block during the first 24 hours after surgery. Secondary outcomes included a slight decrease in opioid requirement in the TAP group, but no difference in occurrence of chronic pain between the two groups. The II/IH block was performed by an experienced provider, but it was a blind block. In a randomized, prospective study, Petersen et al showed that a standard analgesic regimen including ibuprofen and acetaminophen negated any difference between the two regional techniques on AUC pain scores in the first 24 hours. ${ }^{36}$ The reported low pain scores between groups, including the placebo group, made it a challenge to show benefit in either regional anesthetic group, casting doubt on the potential advantages of regional anesthesia in inguinal hernia repair when an aggressive non-opioid technique is employed. Interestingly, pain scores showed that TAP block was inferior to II/IH block in the initial 6 hours after surgery, suggesting that the lateral USG TAP may have sparing of key dermatomes, and the lack of difference is simply due to the short duration of the II/IH block.

A TAP nerve catheter has also been employed in an attempt to show the prolonged analgesic benefits of continuous nerve block after hernia repair. ${ }^{37}$ Unfortunately, this study was small and underpowered and failed to show any analgesic benefit to TAP catheter placement.

\section{Laparoscopic gynecological procedures}

Minor gynecologic procedures are commonly performed in the outpatient setting, providing an appropriate patient population for the evaluation of TAP block benefits. Only a few studies exist, but when compared to placebo, TAP block has been shown to have a role in the postoperative analgesic plan. De Oliveira et al, in a 70-subject study, evaluated the utility of TAP block compared to placebo for outpatient gynecological laparoscopy ${ }^{38}$ The primary endpoint was Quality of Recovery 40 scores, and the authors were able to show a significant improvement in patients receiving both $0.25 \%$ and $0.5 \%$ ropivacaine TAP blocks using the lateral USG technique. Secondary outcomes included pain scores, 24-hour opioid use, and readiness for discharge from the recovery area, and in all areas, the lateral USG TAP block was shown to have a statistically significant benefit. These results were reevaluated by Calle et al in a prospective study showing the role of TAP blocks in ambulatory laparoscopic hysterectomy. ${ }^{39}$ The technique utilized was a laparoscopic-assisted double-pop landmark technique performed by the surgeon. The authors were able to show a statistically significant difference in pain score upon discharge when comparing TAP block to placebo, but this difference was small. On top of that, no difference was noted in opioid consumption or pain score at 24 and 48 hours.

El Hachem et al compared TAP blocks to trocar site infiltration in patients undergoing gynecologic laparoscopy. ${ }^{40}$ Patients received a TAP block on one side and local infiltration on the other, with no difference in pain scores or opioid use noted between the two groups. Of note, both lateral USG 
TAP and surgeon-placed laparoscopic-assisted TAP blocks were studied.

These results add to the overall mixed results in studies evaluating the role of TAP blocks for outpatient surgery. Undoubtedly, randomized controlled studies showing the benefit of lateral USG TAP blocks compared to placebo exist. The benefit in pain outcomes is confirmed by a recent meta-analysis that included both inpatient and outpatient laparoscopic procedures. ${ }^{41}$ Unfortunately, it has been much harder to show any benefit when comparing TAP block to local infiltration at the trocar site or other blocks such as the II/IH block. It may be simply that the USG lateral approach does not include all of the relevant dermatomes, sparing important thoracoabdominal cutaneous branches. There is some promise in the utility of the subcostal approach in laparoscopy compared to trocar infiltration, but further evaluation of this newer block variation as well as the novel USG posterior approach is needed.

\section{ACB}

The ACB is a variation of the femoral nerve block (FNB), performed distally with the intention of sparing quadriceps strength and maintaining the benefits of blocking the innervation to the knee and medial aspect of the lower leg and foot. Thus, the utility of this block is not much different than that of the traditional FNB performed at the level of the femoral crease. The ability to maintain quadriceps strength has been mainly applied to total knee arthroplasty (TKA), where postoperative fall risk and FNB-related weakness have been reported. ${ }^{42,43}$ The dual benefit of postoperative strength and analgesia in femoral nerve distribution is an appealing concept that can also be applied in the ambulatory setting.

\section{Anatomy and technique}

The AC, at times referred to as Hunter's canal or the subsartorial canal, is an aponeurotic tunnel covered by the vastoadductor membrane. By definition, its proximal border is the apex of the femoral triangle and it ends distally at the adductor hiatus. The AC is bound anteromedially by the sartorius, anterolaterally by the vastus medialis, and posteriorly by the adductor longus muscle. It contains femoral vessels and branches from the femoral nerve, including the saphenous nerve and nerve to the vastus medialis muscle. The saphenous nerve is most often located anterolateral to the femoral artery at the proximal portion of the AC, but courses medially on top of the artery as the vessels exit the canal. ${ }^{44}$ Of note, posterior obturator nerve branches may be present within the $\mathrm{AC}$, oftentimes piercing into the distal portion of the AC.

The femoral and obturator nerves both play a role in the complex innervation to the knee and lower leg. In conjunction with the tibial and common peroneal nerves, they form genicular nerves that innervate the knee joint. The majority of the anteromedial and anterolateral parts of the capsule are innervated by the femoral patellar plexus, with a significant contribution coming from the nerve to the vastus medialis. Outside of its sensory component, the nerve to the vastus medialis also has motor function that innervates the vastus medialis muscle - part of the quadriceps. The saphenous nerve innervates the anteromedial cutaneous portion of the knee in the form of its infrapatellar nerve branch, and continues to innervate the medial region of the leg until the ankle. The obturator nerve contributes to knee capsule innervation by being a part of the popliteal plexus and supplies the posteromedial aspect of the knee. The posterior branches that migrate into the AC may partially supply the motor component of the adductors.

Some ambiguity on the identification of the proximal border of the $\mathrm{AC}$ exists, with Bendtsen et al pointing out that the external landmarks of the subsartorial region may inaccurately estimate the location of the $\mathrm{AC} .{ }^{45}$ This is further complicated by the $\mathrm{AC}$ and subsartorial canal terms being used interchangeably, even though the margins of the subsartorial region extend proximal to the AC. Regardless of the exact definition, anatomical studies support that subsartorial injection close to the femoral triangle has minimal cephalad spread. ${ }^{46,47}$

Although early descriptions of a subsartorial block with the use of a twitch monitor exist, it has become exclusively a USG block. ${ }^{48}$ Because of the location of the nerve relative to the artery, the approach typically described is an in-plane anterolateral to medial approach, with the ultrasound probe positioned mid-thigh.

\section{Indications}

The lack of cephalad spread into the femoral triangle has potential clinical implications. Motor innervation to the quadricep muscles often includes parts of the femoral nerve that branch off proximal to the AC. Because of this, the ACB has the potential advantage of maintaining quadriceps strength, with the exception of the vastus medialis muscle, which has motor components within the AC. The clinical application of this has been evaluated. Jaeger et al showed an $8 \%$ reduction in strength in healthy volunteers when $\mathrm{ACB}$ was compared to baseline, but this was nowhere near as drastic as the $49 \%$ 
reduction from baseline in FNB recipients. ${ }^{49}$ The relative preservation of quadriceps strength in ACB recipients was also shown when healthy volunteers were administered both ACB and FNB in opposite limbs..$^{50}$

The maintenance of strength and ability to ambulate after ACB has been reiterated in several randomized, prospective studies in patients undergoing TKA..$^{51,52}$ Compared to placebo, patients who received an $\mathrm{AC}$ peripheral nerve catheter had the expected decrease in morphine consumption, lower pain scores with flexion after TKA, and improved ability to ambulate as measured by the Timed Up and Go (TUG) test. ${ }^{51}$ The analgesic and opioid-sparing benefits of ACB compared to placebo in patients undergoing TKA have been noted. ${ }^{52}$ With the FNB being widely accepted as a key component of the multimodal analgesic plan for TKA, the ability to ambulate early and maintain quadriceps strength while having similar pain scores and opioid use after ACB has been well documented. ${ }^{53-55}$

The ACB has been studied in patients undergoing ambulatory arthroscopic knee surgeries, with mixed results. In patients undergoing medial meniscectomy, improved pain scores and decreased opioid requirement were shown with a distal subsartorial saphenous block using a nerve stimulation technique. ${ }^{56}$ Equally promising results were shown in patients receiving a USG ACB compared to placebo block prior to arthroscopic medial meniscectomy. ${ }^{57}$ Interestingly, when used as a part of a multimodal analgesic plan, the ACB showed little benefit in minor knee arthroscopies. Espelund et al showed that an analgesic regimen including acetaminophen and ibuprofen negated the opioid-sparing benefit of ACB, as well as the resting pain score difference. ${ }^{58}$ Espelund et al also demonstrated no advantages in using the ACB in arthroscopic anterior cruciate ligament (ACL) reconstruction, once again quoting that the benefits of the regional anesthetic technique may be hidden by the multimodal analgesic technique in a situation where postoperative baseline pain scores low. ${ }^{59}$ These results are not expected, given that a majority of studies support the benefit of FNB in ACL reconstruction. ${ }^{60,61}$ Espelund et al were later able to show that, when selecting for patients experiencing moderate-to-severe pain scores post-knee arthroscopy, at rest and walking pain scores improved after an $\mathrm{ACB} .{ }^{62}$ Although the potential utility of ACB in outpatient surgery exists, it needs further investigation.

\section{Pectoral nerves blocks}

Recently, Blanco ${ }^{63}$ and Blanco et al ${ }^{64,65}$ have described a series of thoracic wall fascial plane nerve blocks referred to commonly as pectoral nerves I block (Pecs I), pectoral nerves II block (Pecs II), and serratus plane block, each with a dif- ferent approach to dealing with the complex innervation of the chest. There are several ambulatory procedures that these types of blocks can be applied to, including breast surgery, pacemaker placement, port placement, etc. These novel ultrasound techniques are not all-encompassing and not as definitive as thoracic epidural or paravertebral blocks, but in the outpatient setting, they may provide more utility because of operator hesitancy to perform neuraxial blocks that may have prolonged hemodynamic sequelae. What are currently lacking are significant randomized, prospective studies that show the benefit of these novel blocks. Local wound infiltration by the surgeon for minor chest wall operations is a frequently utilized regional technique which negates the need for understanding the complex sonoanatomy and innervation of the thorax by the anesthesiologist. Nevertheless, a brief review of the anatomy relevant to these blocks and current indications are included.

\section{Anatomy and technique}

Pecs I targets the neurofascial plane between the pectoralis major and pectoralis minor $(\mathrm{Pm})$ muscles with the intention of blocking both the lateral and medial pectoral nerves. The block is performed with the ultrasound probe positioned similar to an infraclavicular brachial plexus block, with the needle position in plane.

Pecs II involves a second fascial plane injection between the Pm muscle and serratus muscle, attempting to block the long thoracic nerve and parts of the intercostal nerves at the level of the injection. Pecs II is performed with the ultrasound probe moved from an infraclavicular to axillary position, close to the lateral border of the Pm muscle above the third rib.

The serratus plane block was developed as an alternative to paravertebral block, primarily affecting the thoracic intercostal nerves. It is performed in the midaxillary region, at the level of the fifth rib, with the local anesthetic deposited either deep or superficial to the serratus muscle.

\section{Indications}

The efficacy of these novel chest wall blocks has not been thoroughly evaluated as of yet. They have potential as an alternative to the gold standard epidural and paravertebral blocks, and the appeal of these blocks for use in the outpatient setting is notable. Bashandy and Abbas, in a prospective, randomized trial that included 120 patients undergoing modified radical mastectomy, were able to show the potential benefits of Pecs I and Pecs II. ${ }^{66}$ Significantly lower VAS scores up to 24 hours after surgery were reported in patients who received both 
the USG Pecs I and Pecs II. Lower postoperative morphine patient-controlled analgesic use and intraoperative opioid use were reported as well. At this time, no studies in the outpatient setting have been performed, but the potential for further evaluation exists.

\section{Novel local anesthetic formulations}

Utility of local anesthetics in treating postoperative pain is limited primarily due to their short duration of action. However, new formulations of local anesthetics, liposomal bupivacaine and $\mathrm{SABER}^{\circledR}$-Bupivacaine, show promise in providing analgesia throughout the entire course of the postoperative period. Here, we provide an overview of the currently available multimodal analgesic options and recommendations for optimal postoperative pain management.

\section{Liposomal bupivacaine}

Liposomal bupivacaine is a new prolonged release formulation of bupivacaine approved by the US Food and Drug Administration (FDA) in 2011 for postsurgical analgesia. ${ }^{67}$ It has been indicated for maximum single-dose administration up to $266 \mathrm{mg}$ at the surgical site. Liposomal bupivacaine can provide drug release for up to 72 hours post-surgery. ${ }^{68}$ No FDA approval has been granted for use in peripheral and neuraxial nerve blocks at this time.

Bupivacaine is an amide local anesthetic. The mechanism of action involves inactivating voltage-gated sodium channels. ${ }^{69}$ Local infiltration of liposomal bupivacaine leads to systemic absorption depending on the site of infiltration. The drug undergoes two releases, a first peak occurring when free bupivacaine in the liposomal solution is systemically absorbed, and a second peak in response to gradual release of liposomal bupivacaine. ${ }^{70}$ Table 1 summarizes the efficacy of liposomal bupivacaine infiltration in surgery that can be performed in an ambulatory setting.

\section{Side effects of liposomal bupivacaine}

Local anesthetics can have multiorgan side effects, with the central nervous system (CNS) most sensitive to toxicity. Early symptoms of paresthesias and dizziness can progress to seizures. ${ }^{71}$ Cardiovascular toxicity requires a higher threshold concentration, with effects including bradycardia, arrhythmias, and eventual cardiac arrest. ${ }^{72} \mathrm{Hu}$ et al reported that the most frequently reported side effects of liposomal bupivacaine administration were nausea, vomiting, constipation, peripheral edema, hypotension, and pyrexia. ${ }^{73}$ Potential cardiac side effects of liposomal bupivacaine were evaluated by Bergese et al. ${ }^{74}$ Liposomal bupivacaine was compared to bupivacaine $\mathrm{HCl}$ in clinically relevant doses in 144 patients who underwent TKA. No significant changes in baseline QRS were found, and similar changes from baseline in heart rate and PR intervals were noted in both groups.

\section{Single-injection PNB}

Ilfeld et al conducted a dose-response study in 14 healthy volunteers with bilateral single-shot FNBs with liposomal bupivacaine. ${ }^{75}$ Doses ranged from $0 \mathrm{mg}$ to $80 \mathrm{mg}$ of liposomal bupivacaine in $30 \mathrm{~mL}$ of normal saline. Two different doses were received by each subject, one on each limb, and were randomly applied in a double-masked fashion. Motor and sensory blockades were evaluated using maximum isovolumetric contraction of the quadriceps femoris muscle, and tolerance to cutaneous electric current in the femoral nerve distribution was assessed.

Results of the study indicated a high degree of intersubject variability and it was found that motor block duration

Table I Efficacy of liposomal bupivacaine in surgical infiltration for potential outpatient surgery

\begin{tabular}{|c|c|c|c|}
\hline Author, year & Surgery & Intervention vs placebo & Key findings \\
\hline Gorfine et al, 201 ${ }^{86}$ & Hemorrhoidectomy & $\begin{array}{l}\text { Liposomal bupivacaine } 300 \mathrm{mg} \\
\text { compared to } 0.9 \% \text { sodium chloride }\end{array}$ & $\begin{array}{l}\text { Pain intensity scores were significantly lower in the } \\
\text { extended-release bupivacaine group vs placebo } \\
(141.8 \text { vs } 202.5, P<0.001)\end{array}$ \\
\hline Smoot et al, $2012^{87}$ & Mammoplasty & $\begin{array}{l}\text { Liposomal bupivacaine } 600 \mathrm{mg} \\
\text { compared to bupivacaine } \mathrm{HCl}\end{array}$ & $\begin{array}{l}\text { No statistical difference was found between the groups } \\
\text { (AUC } 44 \text { I vs } 468, P=0.399 \text { ) }\end{array}$ \\
\hline Golf et al, $\left.201\right|^{88}$ & Bunionectomy & $\begin{array}{l}\text { Liposomal bupivacaine } 120 \mathrm{mg} \\
\text { compared to } 0.9 \% \text { sodium chloride }\end{array}$ & $\begin{array}{l}\text { Pain intensity score was significantly lower with liposomal } \\
\text { bupivacaine vs control (I } 23.9 \text { vs } \mid 46, P<0.0005)\end{array}$ \\
\hline Robbins et al, $2015^{89}$ & Forefoot surgery & $\begin{array}{l}\text { Liposomal bupivacaine compared to } \\
\text { bupivacaine } \mathrm{HCl}\end{array}$ & $\begin{array}{l}\text { Mean number of narcotic pills consumed was } 1.4 \text { and } 1.8 \\
\text { on POD I and } 2 \text {, respectively, compared to } 3.6 \text { on both } \\
\text { days in the control group }\end{array}$ \\
\hline Haas et al, $2012^{90}$ & Hemorrhoidectomy & $\begin{array}{l}\text { Liposomal bupivacaine compared to } \\
\text { bupivacaine } \mathrm{HCl}\end{array}$ & $\begin{array}{l}\text { Lower cumulative pain scores and mean total postoperative } \\
\text { opioid consumption in the liposomal bupivacaine group } \\
\text { compared to the control group }\end{array}$ \\
\hline
\end{tabular}

Abbreviations: AUC, area under the curve; POD, postoperative day. 
could not be correlated with bupivacaine dose. Peak effect of liposomal bupivacaine occurred within 24 hours after block administration in $75 \%$ of subjects. Tolerance to cutaneous stimulation did not return to within $20 \%$ above baseline until 24 hours in all subjects who received a $>40 \mathrm{mg}$ liposomal bupivacaine dose. The study found that the intensity of motor and sensory blockade was inversely related to the dose of liposomal bupivacaine used.

\section{TAP blocks and liposomal bupivacaine}

Hutchins et al investigated the effect of subcostal TAP block with liposomal bupivacaine on postoperative pain relief in patients undergoing robotic-assisted hysterectomy. ${ }^{76}$ A retrospective chart review of patients who underwent roboticassisted hysterectomy between November 2012 and May 2013 was done. The former patients $(n=30)$ were considered as the test population, and patients who received TAP blocks between July 2012 and November 2012 without liposomal bupivacaine $(n=30)$ were the control population. Upon finding the transversus abdominis fascia, three $10 \mathrm{~mL}$ syringes of local anesthetic were injected, with the first one containing $10 \mathrm{~mL}$ of $0.25 \%$ bupivacaine with 1:200,000 epinephrine and the second two syringes containing $5 \mathrm{~mL}$ of liposomal bupivacaine and $5 \mathrm{~mL}$ of preservative-free $0.9 \%$ normal saline. There was a statistically significant decrease in length of hospital stay in the TAPliposomal bupivacaine group compared to the control group (11.5 \pm 8.9 hours vs $27.7 \pm 12.6$ hours, $P<0.001$ ). A randomized, prospective study evaluating the role of liposomal bupivacaine in subcostal TAP in the same patient population has hinted at the long-term (72-hour) opioid-sparing benefit compared to subcostal TAP blocks with bupivacaine $\mathrm{HCl}^{77}$

Sternlicht et al administered liposomal bupivacaine using TAP blocks in laparoscopic prostatectomy patients. ${ }^{78}$ In this single-center, open-label, nonrandomized, prospective study, 12 patients received a total of $20 \mathrm{~mL}$ of $266 \mathrm{mg}$ liposomal bupivacaine and the next 12 received $40 \mathrm{~mL}$ of $266 \mathrm{mg}$ liposomal bupivacaine. Both were diluted in $0.9 \%$ normal saline. The median time to opioid use was 23 and 26 minutes for the 20 and $40 \mathrm{~mL}$ groups, respectively. The range of mean total opioid usage was 25.4-27.3 mg. The mean pain scores reported at the 1-hour mark were 4.4 and 5.3, compared to 3.1 and 3.9 at 2 hours postoperatively, with $20 \mathrm{~mL}$ and $40 \mathrm{~mL}$ doses, respectively. Pain scores were never greater than 3 in both groups.

Feierman et al evaluated liposomal bupivacaine TAP blocks for postsurgical analgesia in open abdominal umbilical hernia repair. ${ }^{79}$ A cohort of 13 patients was administered TAP blocks immediately after surgery using $30 \mathrm{~mL}$ bilateral infiltration of $266 \mathrm{mg}$ liposomal bupivacaine diluted with normal saline. Outcome measures were patient-reported pain sever- ity, postsurgical analgesia satisfaction, and opioid-related adverse events. Pain scores remained less than 2.3 throughout 120 hours postoperatively, and the mean pain score at 10 days was 0.4 . The median time to first opioid use was 11 hours. Analgesia satisfaction at discharge and postoperative day 10 was $54 \%$ and $62 \%$, respectively.

\section{Pectoral nerves blocks and liposomal bupivacaine}

Although, currently, no prospective, randomized studies exist, Leiman et al reported the potential benefits of liposomal bupivacaine in medial and lateral pectoral nerves blocks for management of postsurgical pain after breast augmentation. ${ }^{80}$ The case report involved a 28-year-old woman undergoing elective breast augmentation. Left and right pectoral plane infiltrations were done using a mixture of $10 \mathrm{~mL}$ liposomal bupivacaine and $5 \mathrm{~mL} 0.5 \%$ bupivacaine $\mathrm{HCl}$ on either side. From discharge to postoperative day 10, the patient reported no usage of pain medications. The pain score was consistently below 3, and no pectoral spasms were reported.

\section{SABER ${ }^{\circledR}$-Bupivacaine}

$\mathrm{SABER}^{\circledR}$-Bupivacaine is an extended-release formulation of bupivacaine in a resorbable matrix providing delivery of bupivacaine at the site of administration for a period of 3 days. The three components which make up the formulation are local anesthetic bupivacaine, organic matrix sucrose acetate isobutyrate, and benzyl alcohol, which acts as a diluent. $\mathrm{SABER}^{\circledR}$-Bupivacaine is designed to provide continuous delivery of local anesthetic when placed in surgical wounds at the same rate of $10-20 \mathrm{mg} / \mathrm{h}$ as elastomeric pumps through indwelling catheters. ${ }^{81}$

$\mathrm{SABER}^{\circledR}$-Bupivacaine is instilled into the surgical incision site before wound closure. Following application, the solvent rapidly diffuses, leaving a sustained-release matrix of bupivacaine and sucrose acetate isobutyrate. Clinical pharmacokinetics of SABER ${ }^{\circledR}$-Bupivacaine have been evaluated in patient populations who underwent surgical procedures such as inguinal hernia repair, arthroscopic shoulder repair, laparotomy, laparoscopic cholecystectomy, and laparoscopicassisted colectomy. Absorption of bupivacaine in all surgical models was rapid and was detected within 0.5 hour and 1 hour, followed by a gradual increase in concentration. On a dose-adjusted basis, cumulative exposure of bupivacaine was similar between SABER ${ }^{\circledR}$-Bupivacaine administration and bupivacaine $\mathrm{HCl}$ administration, indicating comparable bioavailability. ${ }^{82}$ Since free bupivacaine provides more relevant information regarding potential CNS and cardiac events than total bupivacaine concentrations, unbound bupivacaine concentrations were elucidated from samples 


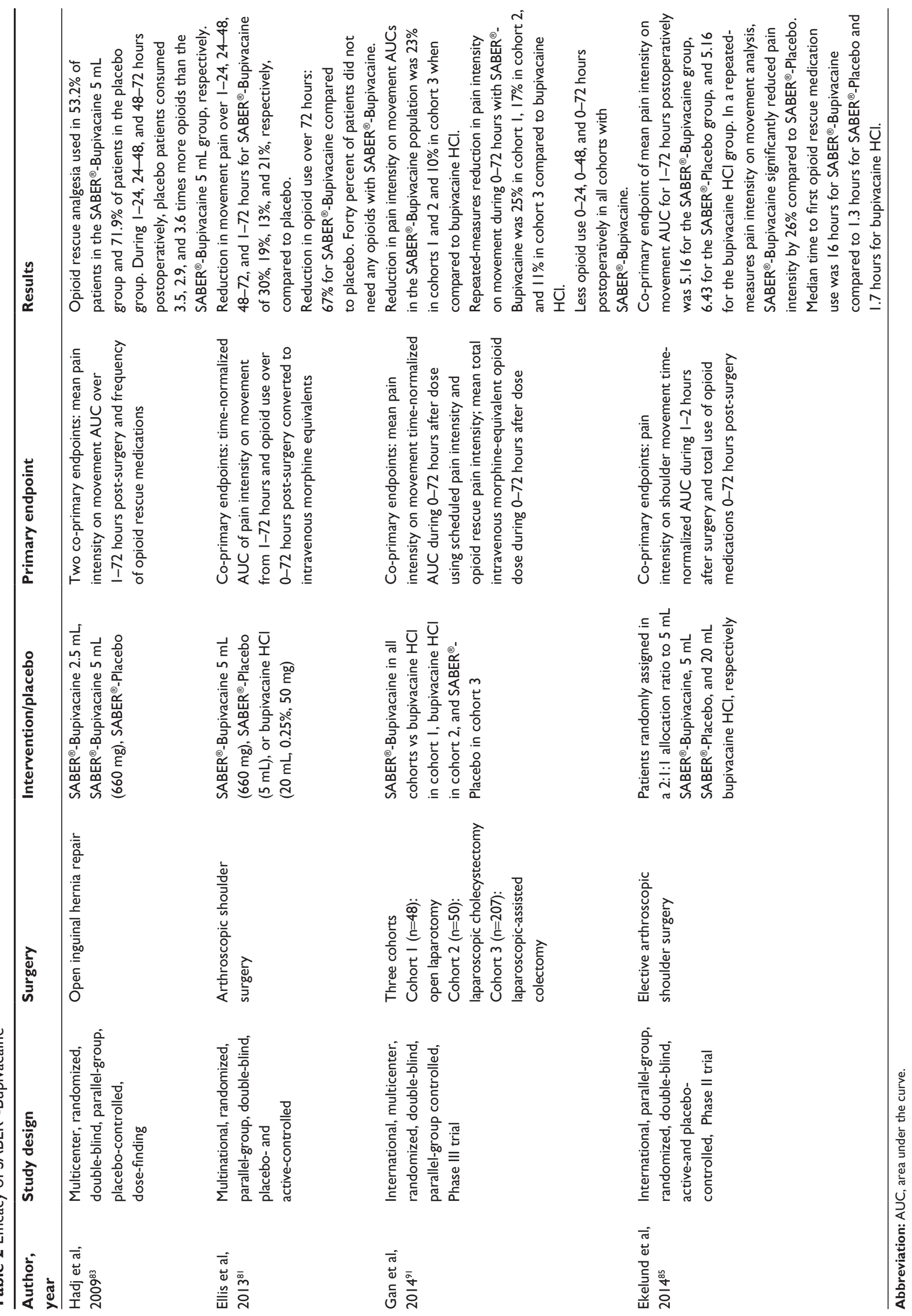


obtained from hysterectomy patients. Results showed mean free plasma bupivacaine concentrations closely paralleling total bupivacaine concentrations, at 5\%-6\% for both SABER ${ }^{\circledR}$-Bupivacaine and bupivacaine $\mathrm{HCl}^{81}$ The efficacy of SABER $^{\circledR}$-bupivacaine in the previously mentioned surgeries is highlighted in Table 2.

\section{Side effects of SABER ${ }^{\circledR}$-Bupivacaine}

Adverse effects of SABER ${ }^{\circledR}$-Bupivacaine were found to be similar to bupivacaine $\mathrm{HCl}$ across multiple studies. Early signs of CNS toxicity were collected by a symptoms questionnaire and cardiac events investigated by 12-lead electrocardiogram and telemetry data pre- and post-dosing. No clinically relevant changes on electrocardiogram were revealed after administration of SABER ${ }^{\circledR}$-Bupivacaine. ${ }^{83}$ In the Ellis et al study, CNS effects observed with SABER ${ }^{\circledR}$-Bupivacaine were at $9.4 \%$, with headache being most common, compared to $13.8 \%$ with bupivacaine $\mathrm{HCl}$. Cardiac events occurred at $1.9 \%$ with SABER $^{\circledR}$-Bupivacaine compared to $10.3 \%$ with bupivacaine $\mathrm{HCl} .{ }^{81}$ Gan et al used Holter monitoring to detect cardiovascular adverse events. Holter monitoring was initiated 1 hour prior to surgery and continued until 72 hours after surgery. Holter data and blood samples for bupivacaine plasma concentration were obtained at baseline and at 1-72 hours after drug dosing. Large procedure-related changes were seen in baseline heart rate, with $\mathrm{SABER}{ }^{\circledR}$-Bupivacaine showing no effect on cardiac conduction or depolarization. ${ }^{84}$ In the Ekelund et al study, the most frequent side effects were headache, nausea, and musculoskeletal pain. Most were mild or moderate in intensity, with no notable differences between treatment groups. Up to 6 months postoperatively, no increased cardiac risk was observed in the $\mathrm{SABER}^{\circledR}$-Bupivacaine group compared to the control groups. ${ }^{85}$

There have been no clinical studies investigating the use of SABER ${ }^{\circledR}$-Bupivacaine in epidurals or PNBs. Considering the superior pharmacodynamic and pharmacokinetic profile of SABER ${ }^{\circledR}$-Bupivacaine to bupivacaine $\mathrm{HCl}, \mathrm{SABER}^{\circledR}$ Bupivacaine promises to be a good candidate for use in regional anesthesia.

\section{Disclosure}

The authors report no conflicts of interest in this work.

\section{References}

1. Cullen KA, Hall MJ, Golosinskiy A. Ambulatory surgery in the United States, 2006. Natl Health Stat Report. 2009;(11):1-25.

2. Macfarlane AJ, Prasad GA, Chan VW, Brull R. Does regional anaesthesia improve outcome after total hip arthroplasty? A systematic review. $\mathrm{Br} J$ Anaesth. 2009;103(3):335-345.
3. Hadzic A, Arliss J, Kerimoglu B, et al. A comparison of infraclavicular nerve block versus general anesthesia for hand and wrist day-case surgeries. Anesthesiology. 2004;101(1):127-132.

4. Martin F, Martinez V, Mazoit JX, et al. Antiinflammatory effect of peripheral nerve blocks after knee surgery: clinical and biologic evaluation. Anesthesiology. 2008;109(3):484-490.

5. Liu SS, Richman JM, Thirlby RC, Wu CL. Efficacy of continuous wound catheters delivering local anesthetic for postoperative analgesia: a quantitative and qualitative systematic review of randomized controlled trials. J Am Coll Surg. 2006;203(6):914-932.

6. Ilfeld BM, Enneking FK. Continuous peripheral nerve blocks at home: a review. Anesth Analg. 2005;100(6):1822-1833.

7. Ilfeld BM. Continuous peripheral nerve blocks in the hospital and at home. Anesthesiol Clin. 2011;29(2):193-211.

8. Abrahams MS, Noles LM, Cross R, Horn JL. Retained stimulating perineural catheters: a report of four cases. Reg Anesth Pain Med. 2011; $36(5): 476-480$.

9. Rafi AN. Abdominal field block: a new approach via the lumbar triangle. Anaesthesia. 2001;56(10):1024-1026.

10. Favuzza J, Delaney CP. Outcomes of discharge after elective laparoscopic colorectal surgery with transversus abdominis plane blocks and enhanced recovery pathway. J Am Coll Surg. 2013;217(3):503-506.

11. Favuzza J, Brady K, Delaney CP. Transversus abdominis plane blocks and enhanced recovery pathways: making the 23-h hospital stay a realistic goal after laparoscopic colorectal surgery. Surg Endosc. 2013; 27(7):2481-2486.

12. Hebbard P. TAP block nomenclature. Anaesthesia. 2015;70(1): $112-113$.

13. McDonnell JG, O'Donnell BD, Tuite D, Farrell T, Power C. The regional abdominal field infiltration (RAFI) technique computerised tomographic and anatomical identification of a novel approach to the transversus abdominis neuro-vascular fascial plain. Anesthesiology. 2004;101:A899.

14. McDonnell JG, O’Donnell B, Curley G, Heffernan A, Power C, Laffey JG. The analgesic efficacy of transversus abdominis plane block after abdominal surgery: a prospective randomized controlled trial. Anesth Analg. 2007;104(1):193-197.

15. McDonnell JG, Curley G, Carney J, et al. The analgesic efficacy of transversus abdominis plane block after cesarean delivery: a randomized controlled trial. Anesth Analg. 2008;106(1):186-191.

16. Jankovic ZB, du Feu FM, McConnell P. An anatomical study of the transversus abdominis plane block: location of the lumbar triangle of Petit and adjacent nerves. Anesth Analg. 2009;109(3):981-985.

17. McDermott G, Korba E, Mata U, et al. Should we stop doing blind transversus abdominis plane blocks? Br J Anaesth. 2012;108(3): 499-502.

18. Rafi AN. Abdominal field block via the lumbar triangle revisited. Anaesthesia. 2012;67(12):1399-1401.

19. Hebbard P, Fujiwara Y, Shibata Y, Royse C. Ultrasound-guided transversus abdominis plane (TAP) block. Anaesth Intensive Care. 2007; 35(4):616-617.

20. McDonnell JG, O'Donnell BD, Farrell T, et al. Transversus abdominis plane block: a cadaveric and radiological evaluation. Reg Anesth Pain Med. 2007;32(5):399-404.

21. Abdallah FW, Chan VW, Brull R. Transversus abdominis plane block: a systematic review. Reg Anesth Pain Med. 2012;37(2):193-209.

22. Hebbard P. Subcostal transversus abdominis plane block under ultrasound guidance. Anesth Analg. 2008;106:674-675.

23. Børglum J, Jensen K, Christensen AF, et al. Distribution patterns, dermatomal anesthesia, and ropivacaine serum concentrations after bilateral dual transversus abdominis plane block. Reg Anesth Pain Med. 2012;37(3):294-301.

24. Blanco R. TAP block under ultrasound guidance: the description of a "no pops" technique. Reg Anesth Pain Med. 2007;32(5 Suppl 1):130.

25. Kadam VR. Ultrasound-guided quadratus lumborum block as a postoperative analgesic technique for laparotomy. J Anaesthesiol Clin Pharmacol. 2013;29(4):550-552. 
26. Petersen PL, Stjernholm P, Kristiansen VB, et al. The beneficial effect of transversus abdominis plane block after laparoscopic cholecystectomy in day-case surgery: a randomized clinical trial. Anesth Analg. 2012; 115(3):527-533.

27. El-Dawlatly AA, Turkistani A, Kettner SC, et al. Ultrasound-guided transversus abdominis plane block: description of a new technique and comparison with conventional systemic analgesia during laparoscopic cholecystectomy. Br J Anaesth. 2009;102(6):763-767.

28. Ra YS, Kim CH, Lee GY, Han JI. The analgesic effect of the ultrasound-guided transverse abdominis plane block after laparoscopic cholecystectomy. Korean J Anesthesiol. 2010;58:362-368.

29. Ortiz J, Suliburk JW, Wu K, et al. Bilateral transversus abdominis plane block does not decrease postoperative pain after laparoscopic cholecystectomy when compared with local anesthetic infiltration of trocar insertion sites. Reg Anesth Pain Med. 2012;37(2): $188-192$.

30. Chen CK, Tan PC, Phui VE, Teo SC. A comparison of analgesic efficacy between oblique subcostal transversus abdominis plane block and intravenous morphine for laparascopic cholecystectomy A prospective randomized controlled trial. Korean J Anesthesiol. 2013; 64(6):511-516.

31. Bhatia N, Arora S, Jyotsna W, Kaur G. Comparison of posterior and subcostal approaches to ultrasound-guided transverse abdominis plane block for postoperative analgesia in laparoscopic cholecystectomy. J Clin Anesth. 2014;26(4):294-299.

32. Tolchard S, Davies R, Martindale S. Efficacy of the subcostal transversus abdominis plane block in laparoscopic cholecystectomy: comparison with conventional port-site infiltration. JAnaesthesiol Clin Pharmacol. 2012;28(3):339-343.

33. Bisgaard T, Klarskov B, Rosenberg J, Kehlet H. Characteristics and prediction of early pain after laparoscopic cholecystectomy. Pain. 2001;90:261-269.

34. Bærentzen F, Maschmann C, Jensen K, Belhage B, Hensler M, Børglum J. Ultrasound-guided nerve block for inguinal hernia repair: a randomized, controlled, double-blind study. Reg Anesth Pain Med. 2012;37: 502-507.

35. Aveline C, Le Hetet H, Le Roux A, et al. Comparison between ultrasound-guided transversus abdominis plane and conventional ilioinguinal/iliohypogastric nerve blocks for day-case open inguinal hernia repair. Br J Anaesth. 2011;106(3):380-386.

36. Petersen PL, Mathiesen O, Stjernholm P, et al. The effect of transversus abdominis plane block or local anaesthetic infiltration in inguinal hernia repair: a randomised clinical trial. Eur J Anaesthesiol. 2013; 30(7):415-421.

37. Heil JW, Nakanote KA, Madison SJ, et al. Continuous transversus abdominis plane (TAP) blocks for postoperative pain control after hernia surgery: a randomized, triple-masked, placebo-controlled study. Pain Med. 2014;15(11):1957-1964.

38. De Oliveira GS Jr, Fitzgerald PC, Marcus RJ, Ahmad S, McCarthy RJ. A dose-ranging study of the effect of transversus abdominis block on postoperative quality of recovery and analgesia after outpatient laparoscopy. Anesth Analg. 2011;113(5):1218-1225.

39. Calle GA, López CC, Sánchez E, et al. Transversus abdominis plane block after ambulatory total laparoscopic hysterectomy: randomized controlled trial. Acta Obstet Gynecol Scand. 2014;93(4):345-350.

40. El Hachem L, Small E, Chung P, et al. Randomized controlled double-blind trial of transversus abdominis plane block versus trocar site infiltration in gynecologic laparoscopy. Am J Obstet Gynecol. 2015;212(2):182. e1-e9.

41. De Oliveira GS Jr, Castro-Alves LJ, Nader A, Kendall MC, McCarthy RJ. Transversus abdominis plane block to ameliorate postoperative pain outcomes after laparoscopic surgery: a meta-analysis of randomized controlled trials. Anesth Analg. 2014;118(2):454-463.

42. Atkinson HD, Hamid I, Gupte CM, Russell RC, Handy JM. Postoperative fall after the use of the 3-in-1 femoral nerve block for knee surgery: a report of four cases. J Orthop Surg (Hong Kong). 2008; 16(3):381-384.
43. Ilfeld BM, Duke KB, Donohue MC. The association between lower extremity continuous peripheral nerve blocks and patient falls after knee and hip arthroplasty. Anesth Analg. 2010;111(6):1552-1554.

44. Kapoor R, Adhikary SD, Siefring C, McQuillan PM. The saphenous nerve and its relationship to the nerve to the vastus medialis in and around the adductor canal: an anatomical study. Acta Anaesthesiol Scand. 2012;56(3):365-367.

45. Bendtsen TF, Moriggl B, Chan V, Pedersen EM, Børglum J. Redefining the adductor canal block. Reg Anesth Pain Med. 2014;39(5): $442-443$.

46. Ishiguro S, Yokochi A, Yoshioka K, et al. Technical communication: anatomy and clinical implications of ultrasound-guided selective femoral nerve block. Anesth Analg. 2012;115(6):1467-1470.

47. Cowlishaw P, Kotze P. Adductor canal block - or subsartorial canal block? Reg Anesth Pain Med. 2015;40(2):175-176.

48. Benzon HT, Sharma S, Calimaran A. Comparison of the different approaches to saphenous nerve block. Anesthesiology. 2005; 102(3):633-638.

49. Jaeger P, Nielsen ZJ, Henningsen MH, Hilsted KL, Mathiesen O, Dahl JB. Adductor canal block versus femoral nerve block and quadriceps strength: a randomized, double-blind, placebocontrolled, crossover study in healthy volunteers. Anesthesiology. 2013;118(2):409-415.

50. Kwofie MK, Shastri UD, Gadsden JC, et al. The effects of ultrasoundguided adductor canal block versus femoral nerve block on quadriceps strength and fall risk: a blinded, randomized trial of volunteers. Reg Anesth Pain Med. 2013;38(4):321-325.

51. Jenstrup MT, Jæger P, Lund J, et al. Effects of adductor-canal-blockade on pain and ambulation after total knee arthroplasty: a randomized study. Acta Anaesthesiol Scand. 2012;56(3):357-364.

52. Hanson NA, Allen CJ, Hostetter LS, et al. Continuous ultrasoundguided adductor canal block for total knee arthroplasty: a randomized, double-blind trial. Anesth Analg. 2014;118(6):1370-1377.

53. Grevstad U, Mathiesen O, Lind T, Dahl JB. Effect of adductor canal block on pain in patients with severe pain after total knee arthroplasty: a randomized trial with individual patient analysis. Br J Anaesth. 2014; 112(5):912-919.

54. Kim DH, Lin Y, Goytizolo EA, et al. Adductor canal block versus femoral nerve block for total knee arthroplasty: a prospective, randomized, controlled trial. Anesthesiology. 2014;120(3):540-550.

55. Shah NA, Jain NP. Is continuous adductor canal block better than continuous femoral nerve block after total knee arthroplasty? Effect on ambulation ability, early functional recovery and pain control: a randomized controlled trial. J Arthroplasty. 2014;29(11): 2224-2229.

56. Akkaya T, Ersan O, Ozkan D, et al. Saphenous nerve block is an effective regional technique for post-menisectomy pain. Knee Surg Sports Traumatol Arthrosc. 2008;16(9):855-858.

57. Hanson NA, Derby RE, Auyong DB, et al. Ultrasound-guided adductor canal block for arthroscopic medial meniscectomy: a randomized, double-blind trial. Can J Anaesth. 2013;60(9):874-880.

58. Espelund M, Fomsgaard JS, Haraszuk J, Dahl JB, Mathiesen O. The efficacy of adductor canal blockade after minor arthroscopic knee surgery - a randomised controlled trial. Acta Anaesthesiol Scand. 2014;58(3):273-280.

59. Espelund M, Fomsgaard JS, Haraszuk J, Mathiesen O, Dahl JB. Analgesic efficacy of ultrasound-guided adductor canal blockade after arthroscopic anterior cruciate ligament reconstruction: a randomised controlled trial. Eur J Anaesthesiol. 2013;30(7):422-428.

60. Williams BA, Kentor ML, Vogt MT, et al. Reduction of verbal pain scores after anterior cruciate ligament reconstruction with 2-day continuous femoral nerve block: a randomized clinical trial. Anesthesiology. 2006;104(2):315-327.

61. Dauri M, Fabbi E, Mariani P, et al. Continuous femoral nerve block provides superior analgesia compared with continuous intra-articular and wound infusion after anterior cruciate ligament reconstruction. Reg Anesth Pain Med. 2009;34(2):95-99. 
62. Espelund M, Grevstad U, Jaeger P, et al. Adductor canal blockade for moderate to severe pain after arthroscopic knee surgery: a randomized controlled trial. Acta Anaesthesiol Scand. 2014;58(10):1220-1227.

63. Blanco R. The 'pecs block': a novel technique for providing analgesia after breast surgery. Anaesthesia. 2011;66(9):847-848.

64. Blanco R, Fajardo M, Parras Maldonado T. Ultrasound description of Pecs II (modified Pecs I): a novel approach to breast surgery. Rev Esp Anestesiol Reanim. 2012;59(9):470-475.

65. Blanco R, Parras T, McDonnell JG, Prats-Galino A. Serratus plane block: a novel ultrasound-guided thoracic wall nerve block. Anaesthesia. 2013;68(11):1107-1113.

66. Bashandy GM, Abbas DN. Pectoral nerves I and II blocks in multimodal analgesia for breast cancer surgery: a randomized clinical trial. Reg Anesth Pain Med. 2015;40(1):68-74.

67. Exparel ${ }^{\circledR}$ (bupivacaine liposome) injectable suspension [prescribing information]. Parsippany: Pacira Pharmaceuticals, Inc.; 2014.

68. Richard BM, Rickert DE, Newton PE, et al. Safety evaluation of EXPAREL (DepoFoam bupivacaine) administered by repeated subcutaneous injection in rabbits and dogs: species comparison. J Drug Deliv. 2011;2011:467429.

69. Agarwal N, Kalra VK. Studies on the mechanism of action of local anesthetics on proton translocating ATPase from Mycobacterium phlei. Biochim Biophys Acta. 1984;764(3):316-323.

70. Chapman PJ. Review: bupivacaine - a long acting local anaesthetic. Aust Dent J. 1987;32(4):288-291.

71. Wolfe JW, Butterworth JF. Local anesthetic systemic toxicity: update on mechanisms and treatment. Curr Opin Anaesthesiol. 2011;24(5): 561-566.

72. Mulroy MF. Systemic toxicity and cardiotoxicity from local anesthetics: incidence and preventive measures. Reg Anesth Pain Med. 2002; 27(6):556-561.

73. Hu D, Onel E, Singla N, Kramer WG, Hadzic A. Pharmacokinetic profile of liposome bupivacaine injection following a single administration at the surgical site. Clin Drug Invest. 2013;33(2):109-115.

74. Bergese SD, Ramamoorthy S, Patou G, Bramlett K, Gorfine SR, Candiotti KA. Efficacy profile of liposome bupivacaine, a novel formulation of bupivacaine for postsurgical analgesia. J Pain Res. 2012;5:107-116.

75. Ilfeld BM, Malhotra N, Furnish TJ, Donohue MC, Madison SJ. Liposomal bupivacaine as a single-injection peripheral nerve block: a doseresponse study. Anesth Analg. 2013;117(5):1248-1256.

76. Hutchins J, Vogel RI, Ghebre R, et al. Ultrasound-guided subcostal transversus abdominis plane infiltration with liposomal bupivacaine for patients undergoing robotic-assisted hysterectomy: a retrospective study. Int J Gynecol Cancer. 2015;25(5):937-941.

77. Hutchins J, Delaney D, Vogel RI, et al. Ultrasound guided subcostal transversus abdominis plane (TAP) infiltration with liposomal bupivacaine for patients undergoing robotic assisted hysterectomy: a prospective randomized controlled study. Gynecol Oncol. 2015; 138(3):609-613.

78. Sternlicht A, Shapiro M, Robelen G, Vellayappan U, Tuerk IA. Infiltration of liposome bupivacaine into the transversus abdominis plane for postsurgical analgesia in robotic laparoscopic prostatectomy: a pilot study. Local Reg Anesth. 2014;7:69-74.

79. Feierman DE, Kronenfeld M, Gupta PM, Younger N, Logvinskiy E. Liposomal bupivacaine infiltration into the transversus abdominis plane for postsurgical analgesia in open abdominal umbilical hernia repair: results from a cohort of 13 patients. J Pain Res. 2014;7:477-482.

Ambulatory Anesthesia

\section{Publish your work in this journal}

Ambulatory Anesthesia is an international, peer reviewed, open access journal publishing articles that address all aspects of ambulatory anesthesia practice, in particular: anesthetic techniques, sedation and safety practices, pharmacokinetics, preoperative evaluation, analgesia interventions, regulatory and compliance issues, postoperative recovery,

Submit your manuscript here: http://www.dovepress.com/ambulatory-anesthesia-journal
80. Leiman D, Barlow M, Carpin K, Piña E, Casso D. Medial and lateral pectoral nerve block with liposomal bupivacaine for the management of postsurgical pain after submuscular breast augmentation. Plast Reconstr Surg Glob Open. 2015;2(12):e282.

81. Ellis D, Verity N, Lissin D, Wendicke-Lophaven K. Treatment of postoperative pain in shoulder surgery with SABER ${ }^{\circledR}$-bupivacaine. Abstract Number 433. Presented at: American Pain Society 32nd Annual Scientific Meeting; May 8, 2013; New Orleans, LA.

82. Shah J, Ellis D, Verity N. Pharmacokinetic characteristics of SABER ${ }^{\circledR}$ Bupivacaine in humans demonstrate sustained drug delivery for up to 72 hours in a variety of surgical models. Poster presented at: 39th Annual American Society of Regional Anesthetic and Pain Medicine Meeting; April 3-6; 2014; Chicago, IL.

83. Hadj A, Nicholson D, Moddie J, et al. SABER ${ }^{\circledR}$-Bupivacaine, a novel extended-release formulation of bupivacaine for postoperative pain control demonstrates dose-response, safety and no impact on surgical wound healing following inguinal herniorrhaphy. Abstract number SE2009-5077. Presented at: American College of Surgeons 95th Annual Clinical Congress; October 12, 2009; Chicago, IL.

84. Gan TJ, Fossa A, Zhou M, et al. The cardiac safety of SABER ${ }^{\circledR}$-Bupivacaine in patients undergoing abdominal surgery: an assessment of Holter monitoring data from the BESST trial. Presented at: Anesthesia Research Society 2014 Annual Meeting and International Science Symposium; May 17-20, 2014; Montreal, QC.

85. Ekelund A, Peredistijs A, Grohs J, et al. Treatment of postoperative pain in shoulder surgery with SABER ${ }^{\circledR}$-Bupivacaine. Poster presented at: 39th Annual American Society of Regional Anesthetic and Pain Medicine Meeting; April 3-6; 2014; Chicago, IL.

86. Gorfine SR, Onel E, Patou G, Krivokapic ZV. Bupivacaine extendedrelease liposome injection for prolonged postsurgical analgesia in patients undergoing hemorrhoidectomy: a multicenter, randomized, double-blind, placebo-controlled trial. Dis Colon Rectum. 2011;54(12): 1552-1559.

87. Smoot JD, Bergese SD, Onel E, Williams HT, Hedden W. The efficacy and safety of DepoFoam bupivacaine in patients undergoing bilateral, cosmetic, submuscular augmentation mammaplasty: a randomized, double-blind, active-control study. Aesthetic Surg J. 2012;32(1): 69-76.

88. Golf M, Daniels SE, Onel E. A phase 3, randomized, placebo-controlled trial of DepoFoam ${ }^{\circledR}$ bupivacaine (extended-release bupivacaine local analgesic) in bunionectomy. Adv Ther. 2011;28(9):776-788.

89. Robbins J, Green CL, Parekh SG. Liposomal bupivacaine in forefoot surgery. Foot Ankle Int. 2015;36(5):503-507.

90. Haas E, Onel R, Miller H, Ragupathi M, White PF. A double-blind, randomized, active-controlled study for post-hemorrhoidectomy pain management with liposome bupivacaine, a novel local analgesic formulation. Am Surg. 2012;78(5):574-581.

91. Gan TJ, Papaconstantinou H, Durieux M, et al. Treatment of postoperative pain in major abdominal surgery with $S A B E R^{\circledR}$-Bupivacaine: results of the BESST trial. Poster presented at: 39th Annual American Society of Regional Anesthetic and Pain Medicine Meeting; April 3-6; 2014; Chicago, IL.

\section{Dovepress}

patient satisfaction, administrative topics, and cost analysis themes. The manuscript management system is completely online and includes a very quick and fair peer review system, which is all easy to use. Visit $\mathrm{http}: / /$ www.dovepress.com/testimonials.php to read real quotes from published authors. 